\section{OPEN ACCESS}

*King Abdullah University of Science and Technology (KAUST)

Corresponding author email address: carlos.duarte@kaust.edu.sa 10.5339/qproc.2015.qulss2015.1

Copyright: 2015 Carlos M. Duarte, licensee Bloomsbury Qatar Foundation Journals. This is an open access article distributed under the terms of the Creative Commons Attribution license CC BY 4.0, which permits unrestricted use, distribution and reproduction in any medium, provided the original work is properly cited.

\title{
Global change in marine ecosystems: Implications for semi- enclosed Arabian seas
}

\author{
Carlos M. Duarte*
}

Global Change has been defined as the impact of human activities on the key processes that determine the functioning of the Biosphere. Global Change is a major threat for marine ecosystems and includes climate change as well as other global impacts such as inputs of pollutants, overfishing and coastal sprawl. The Semi-enclosed Arabian Seas, including the Arabian Gulf and the Red Sea, have supported human livelihoods in the Arabian Peninsula over centuries and continue to do so, but are also threatened by Global Change. These threats are particularly severe as Semi-enclosed Arabian Seas already present rather extreme conditions, in terms of temperature, salinity and oxygen concentration. The vulnerability of the unique marine ecosystems of the Semi-enclosed Arabian Seas to Global Change vectors is largely unknown, but predictions based on first principles suggest that they may be at or near the tipping point for many pressures, such as warming and hypoxia. There is an urgent need to implement international collaborative research programs to accelerate our understanding of the vulnerability of Semi-enclosed Arabian Seas to Global Change vectors in order to inform conservation and management plans to ensure these Seas continue to support the livelihoods and well-being of the Arab nations. 